NBSIR 73.421

An Overview of the Factors Impacting Metrication of the U. S. Housing Industry

Robert G. Hendrickson

Donald W. Corrigan

Technical Analysis Division National Bureau of Standards

Washington, D. C. 20234

December, 1973

Final

Prepared for

Office of Policy Development and Research

Department of Housing and Urban Development

Washington, D. C. 

NBSIR 73-421

\section{AN OVERVIEW OF THE FACTORS IMPACTING \\ METRICATION OF THE U. S. HOUSING INDUSTRY}

Robert G. Hendrickson

Donald W. Corrigan

Technical Analysis Division

National Bureau of Standards

Washington, D. C. 20234

December, 1973

Final

Prepared for

Office of Policy Development and Research

Department of Housing and Urban Development

Washington, D. C.

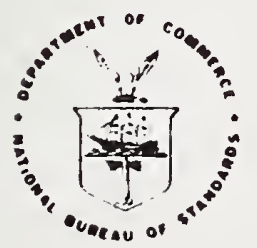

U. S. DEPARTMENT OF COMMERCE, Frederick B. Dent, Secretary

NATIONAL BUREAU OF STANDARDS, Richard $w$. Roberts. Director 
This report describes the work undertaken to ascertain and describe major problems associated with metrication of the U. S. housing industry. Source material included foreign experience with conversion, information obtained from interviews, and depositions provided to the 1970 Construction Conference of the U. S. Metric study. The results indicated a wide range of possible effects, but the most serious problems are expected with coordination, contracts, standards, and the technical aspects of equipment change and dual inventory.

The principal impact of converting the building industry to the metric system will be the redefinition or accommodation of the 15,000 codes at the local level, and the coordination of the more than 100 sources of building standards in the United States to define, develop and implement standards consonant with metrication. The magnitude of this issue is without precedent: no country, now metric or going metric, has a domestic housing industry remotely approaching in size that of the U. S. in terms of the market, number of codes and standards to be addressed, and the number of standard-setting groups or the number of individual firms which will be affected.

The essential impact of metrication in the housing industry will be in its administration rather than in its technical implementation for it appears that problems of adapting codes and standards, sustaining dual inventory costs, and contractual negotiations will be far more dominant than the problems of technology conversion, quality control or product performance criteria.

The assessment of conversion as given in this report suggests that the problems of metrication are predominantly technical or administrative, should not impede conversion and costs are not expected to be significant. Conversion will present opportunities to achieve more uniformity in building codes and standards, and serve as an incentive to obtain the full benefits of dimensional coordination and modular technology. 
Executive Summary

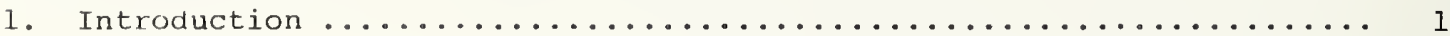

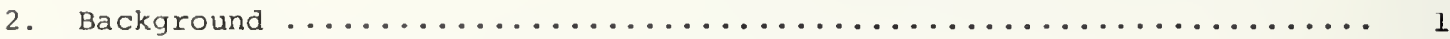

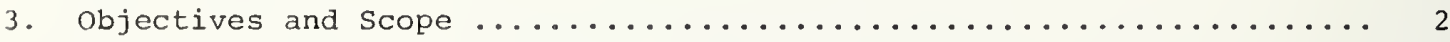

4. Findings: Part I - Conditional Considerations ................

A. Mandatory/Voluntary Programs of Conversion ................ 2

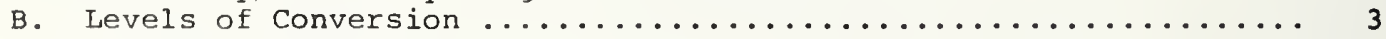

C. Problem severity .................................. 4

Findings: Part II - Metrication Experience ..................

A. Foreign Experience ................................

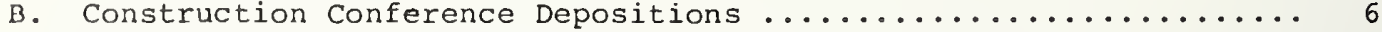

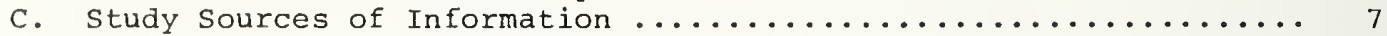

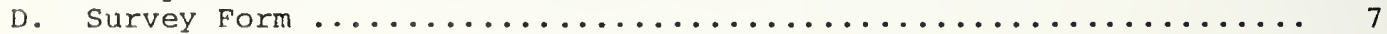

Findings: Part III - study Results $\ldots \ldots \ldots \ldots \ldots \ldots \ldots$

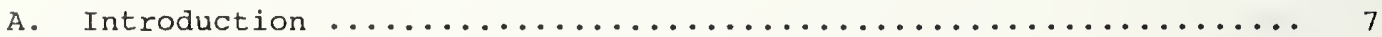

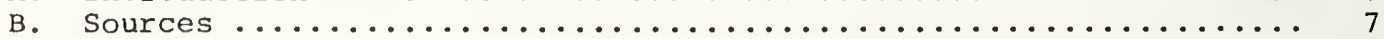

C. Results ...................................... 7

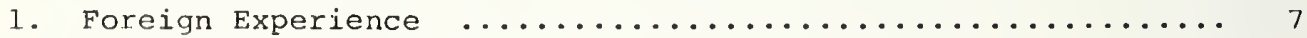

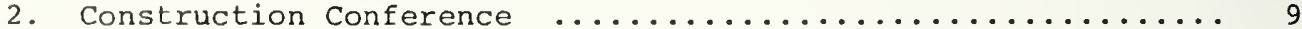

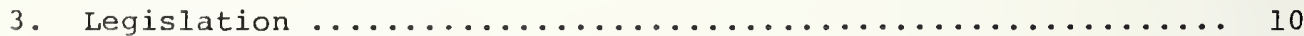

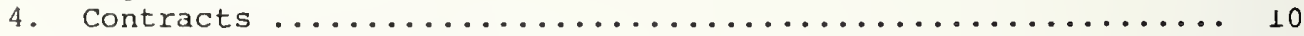

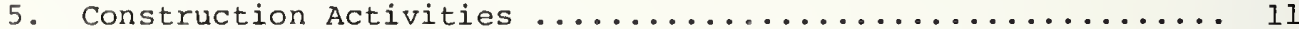

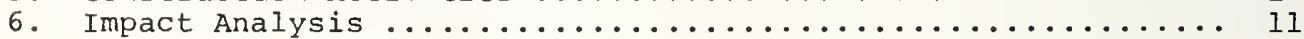

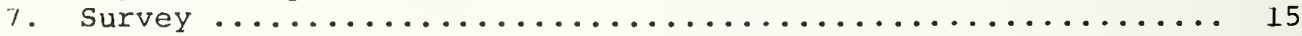

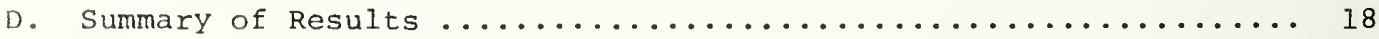

Appendix A - Summary Analysis of 1970 Construction Conference, U.S.

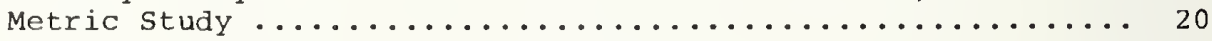

Appendix B - In Britain They've -- "Thought Metric" ............... 22 


\section{INTRODUCTION}

This report documents the work undertaken by the Decision Systems Section, Technical Analysis Division, IAT, for the Department of Housing and Urban Development, on the determination of problems which might be incurred by the U. S. Domestic Housing Industry upon the assumption of conversion to the metric system.

There are three major portions of the paper: Background, Objectives and Scope, and Findings.

The Background describes the scenario and environment of interest in metrication and the stimulation of activity surrounding this subject. The objectives and scope present the intent, concept of study goals, and tasks to be performed. The Findings are divided into three parts. Part I, Conditional Considerations, discusses material and subjects pertinent to conversion, attitudes and points of view, impact, and circumstances attendant to the process of conversion. Part II, Metrication Experience, examines details of the problems obtained from foreign experiences, domestic meetings, study interviews, and the information developed from the investigations of the study. Part III, Study Results, explicates the study results, analysis of data and a final summary of problem areas.

The report is supported by the inclusion of two appendices, both containing direct sources of information, and two exhibits supplementing the analysis.

\section{BACKGROUND}

Pursuant to the direction of Congress the National Bureau of Standards was directed to undertake the U. S. Metric Study, which was completed in 1971 with recommendations for adoption of the metric system. Its purpose was to evaluate in broad terms the impact of metric conversion on American industry, science and technology, and to consider alternatives for national policy. The United States remains as the single major user of the customary system. This is not to imply that the rest of the world is purely metric, for this is not so, but the intercourse of science, technology and international exchange is predominantly in the metric system of weights and measures. Consequently, the momentum for a decisive commitment to metric is greater than ever before and most of the rationale for rejection in the past has fallen away.

Metrication in the United Kingdom got underway in 1965 when the Government acted upon the initiative of the Federation of British Industries to convert British Industry. The construction industry was one of the first to undertake the change. Similarly, the Australian building and construction industry was the first industrial sector to agree on a timetable for metric conversion. The general climate, then, is for a change to metric, and with Congressional activity now in evidence in both Houses, it appears the United States is not far from establishing its own program in the immediate future.

As a part of the U. S. Metric Study a series of conferences was conducted by the National Bureau of Standards. The conferences for the Construction Industry assessed the special benefits and problems of increasing metric usage on all aspects of the construction industry. Spokesmen presented reports in sessions on: building design, building codes and standards, building materials, production and sales, general contractors and subcontractors, building core construction, house builders and home manufacturers, land services and heavy construction. As indicated in Appendix A, several sessions over a two-day period provided an exchange of perceptions on the overall impact of metrication on construction, including domestic housing as a part of the scope of the conference. Many questions remained, especially on levels of complexity of anticipated problem areas and the likelihood that U. S. experience might parallel the adoption of the metric system abroad.

This report attempts to delineate the most probable problem areas for the domestic housing industry in converting to metric which are judged to require further study or an in-depth investigation to determine the extent of their impact and resolution. 


\section{Objectives}

The objective of this study was to identify probable major problems associated with the conversion of the domestic United States housing industry to the metric system of measurement, and the manufacture and use of products based on metric dimensions and standards. A "major problem" is defined for this study as one which would inhibit or delay conversion to metric and require an extensive study to determine its appropriate resolution. Estimates of the magnitude and impact of potential problems should provide insight to their solution and assist in planning for conversion.

\section{Scope}

The problems of interest include aspects of the construction process not directly related to conversion, such as administrative overhead, instruction, contracts, legislation, direct or indirect costs and economic factors. Information on problems of conversion were sought from other countries with metric experience, appropriate conferences on the subject, individuals and companies in the housing industry with experience or opinions on the subject. The central purpose has been to identify and highlight those problems of conversion whose impact and resolution require further study. This study does not address the desirability of conversion, only the major problems associated with it.

\section{Assumptions}

The assumptions or conditions inherent in the source material temper any motiviation to draw absolute conclusions about the magnitude and impact of conversion. The British, for example, have a larger export market in construction than the U. S. and is tied closely to the European Common Market, where metric is standard. On the other hand, the Australians and Canadians have, although large for these countries, a smaller domestic market for housing construction than the U. S. Also the technologies differ in quantity and quality; and the national programs of Great Britain and Australia are encouraged to convert to metric by official assistance. The impact of metrication is tied closely to the degree and extent of industry coordination and cooperation within the guidelines and structure of a national program.

The essential danger of applying foreign experience to the U. S. conversion without understanding the differences might lead to conclusions which are incorrect in regard to scope and magnitude. When a formal conversion program is established, the U. S. conversion to metric may have similarities with foreign experience, but the extent and size of the undertaking will be without parallel.

\section{FINDINGS: PART I - CONDITIONAL CONSIDERATIONS}

Part I of this Section on Findings discusses the qualitative and conceptual aspects of several major conditions surrounding metrication and some of the principal intricacies that bear on the impact of conversion.

Part II of this section reviews and presents a partial background of information on the principal sources available to the study.

Part III presents the analysis, evaluation and interpretation of the developed material as it relates to the identification and description of impacts of metrication and associated problem areas.

\section{A. Mandatory/Voluntary Programs of Conversion}

It is an interesting aspect of the study to ascertain the impact a metrication program may have upon its participants. At the present time the United states has no official program for conversion but several legislative bills now pending before Congress indicate that an official national program is not far from being enacted. The act of converting from customary to the metric system may involve the participants in a wide range of possible problems of varying magnitudes, but the program itself may produce the most serious problems to conversion, although it is the expressed objective of the program to expedite the conversion. That a program is necessary is axiomatic, but getting an industry to move toward conversion as a totality spawns problems of coordination and cooperation which are, in most cases, more critical to the success of the conversion than the metrication of the underlying technology. 
Programs for metrication are of three kinds. The first is a no-plan voluntary program, the second, a planned voluntary program, and the third, a planned mandatory program. The principal difference between a mandatory and voluntary program is one of implied penalties for failing to convert by a certain specified target date. It implies that certain conditions are established such that economic penalities are incurred by any business entity failing to convert; but the penalty occurs by virtue of the failure, not from any violation of constraints of the conversion program. By way of example of the no-plan voluntary program, if it can be called a program at all, although the use of the metric system in the United States was authorized in 1866 and the metric measurements standards of the customary system have been in use since 1893, the United States is still essentially on the customary system.

The British and Australian conversion programs are predominantly planned and voluntary but are given additional impetus by governmental controls over statutory regulations, certification of measuring instruments and equipment, and by virtue of the Government being a major procurer of goods and services for public housing projects. These tangible encouragements give the planned voluntary program a stimulus for rapid conversion that might otherwise not exist if the government sector housing development was not so large. Conversion under a mandatory program implies certain inherent penalties may devolve upon those who fail to convert; similarly, conversion under a noplan voluntary program implies that certain inherent penalties may devolve upon those who do convert. The essential quality provided by a planned program is one of coordination, planning, seeking cooperation and, above all else, having the entities of the industry being converted move together as a unit toward desired common objectives. It should be noted, however, that whether a program for conversion is planned-voluntary or mandatory, its success is predicated not so much on the organization of the program, but rather on the conditions and circumstances of the conversion process which motivate or threaten business entities in their perception of general objectives. Coordination and planning are successful in enhahcing the changeover only to the extent they are accepted by the participants and tested against value-judgments made by the participants on cost and benefit factors. It is this point that suggests that a planned voluntary program for a domestic industry would be more effective with some additional incentive or stimulation being provided in some form. The usual arguments for metrication concerning efficiency, standardization, etc., though valid and almost universally accepted, have not provided sufficient motivation for many industries in the United States to convert on a purely voluntary, no-plan basis. The motivation to convert is tied to economic considerations, rather than conversion for its own virtue.

In both Great Britain and Australia the housing industry was among the first to convert to the metric system. The motivation for the industry in Great Britain was based upon a large public-sector program for housing products, large export movements of dimensionally coordinated products, and the desire to accommodate themselves to opportunities afforded by their membership in the European Common Market. In Australia, also, there is the large market provided by government housing projects and the business with other metric countries which provided the underlying desire to obtain metrication quickly and efficiently. Although some of these motivations are not comparably present in the domestic American housing industry on the same scale as in the U. K., Australia and Canada, public housing was nearly one-fourth of all new-residential construction in 1971.

The opinions expressed by participants in the Construction Conference of 1970 , held as a part of the U. S. Metric Study effort, show that although a majority consensus favors conversion to metric, they felt that a voluntary program will not achieve the desired results. The Federal government then is faced with the problem of providing leadership and motivation to an industry of immense proportions, highly fractionated, of small export business while at the same time rapidly standardizing its manufacture and tectonics in the customary system. The problem in doing this lies less in converting the technology but more in the coordination and planning of the actions to be taken by the business entities of the industry.

\section{B. Levels of Conversion}

A meaningful and effective conversion to the metric system is one that not only employs the commercial system of weights and measures in business, but also includes the advantages of the system in obtaining efficiency in calculation, easier coordination of materials and product varieties, and the development of the full potential of coordinated dimensions and modularity. 
To obtain the greatest advantage of metrication requires a graduated program which moves the process from the simplest and most direct expression of metric use through intermediate development of metric standards to the fullest application of the metric system to the technology of construction in all of its phases from design to finished products.

This process begins with what is referred to as soft conversion. A soft conversion is a direct computation of the metric equivalent of a customary dimension, which is then rounded, up or down, to the nearest convenient metric value.* As an example, the foot, consisting of 12 inches is, upon conversion to metric, 304.8 millimeter (mm). Rounding to the nearest millimeter yields $305 \mathrm{~mm}$. Soft conversion entails two concepts: converting and rounding to the nearest metric integral equivalent or converting and rounding to the nearest convenient metric equivalent. The former presents no hardship to business entities as long as the metric equivalent is close enough to the customary that the difference is usually well within acceptable tolerances. The latter conversion presents a different problem. The conversion to an accepted or common dimension, which may be a dramatic change in the product manufacture, immediately brings the producer against the problems of equipment modification and possible market adjustments.

The second step in the conversion process has two parts. The first part is the industry-wide preparation of the development and acceptance of preferred dimensional and product manufacturing standards. The second part is the hard conversion by industry segments to these standards and processes. Using our example, assume that a dimension of $300 \mathrm{~mm}$ is the industry standard. This is a marked deviation from the customary unit of one foot and has consequences to commerce ranging from design changes, new or adjusted manufacturing processes, coordinated product creation, quality control, through construction operations.

The last phase of the conversion is the transition from the level of hard conversion to the development and application of systems approaches to construction using modular and industrialized pre-fabrication technology. These technologies are current today, and this report does not suggest that metric conversion is necessary to their ultimate utilization; but it is suggested that metric conversion offers an opportunity for a greater application of these technologies through the standardization and efficiency that may be gained by the conversion. Appropriate planning would undoubtedly have the second and third phases in some form of parallel development.

\section{Problem Severity}

The problems associated with metrication may be classified into three broad areas: technical, administrative and economic. Exhibit I contains a listing of 23 activities of the housing construction process which may be affected in some degree by metrication and the level of conversion. Within these activities, and the three broad areas, the problems may range from insignificance, as measured by costs of inconvenience, to those which are so severe as to cause a delay in, or inhibit, the intended program of conversion.

In the interest of clarity and analysis, four levels of problem severity are proposed:

1) Ist level problems - those whose impact impede the conversion to metric and require an in-depth study by an industry segment to resolve

2) 2nd level problems - those whose impact impede the conversion to metric and require an in-depth study by a company or business entity to resolve

3) 3rd level problems - those whose impact does not impede conversion to metric and are resolved with minor inconvenience and low attendant costs

4) 4th level problems - those whose impacts are negligible and accommodation to metric conversion is easy, direct and rapid.

With the three areas given above it is possible to examine twelve area-problem level combinations pertinent to the impact of metrication on the domestic housing industry; some of these may involve cross-dependencies. An additional area-level combination may be added to the twelve defined above pertaining to legislative modifications and amendments necessary to the conversion process. Although external to the housing industry, it is necessary that contracts, tenders, codes, and claims

* Soft conversion also implies straight conversion with no rounding. 
proceed on a basis wherein the law has accommodated the metric system and anticipated potential problems.

In rounding out the qualitative description of problem severity it is important to note that problems have additional features, i.e., they are anticipated, and in retrospect, materialize; they are not anticipated and materialize, or they are anticipated, and in retrospect, did not materialize. It is important that business entities examine the experience of foreign counterparts and utilize appropriate professional resources in their preparation for conversion.

\section{FINDINGS: PART II - METRICATION EXPERIENCE}

\section{A. Foreign Experience with Metrication}

An important source of information regarding problems associated with metrication resides with those who have actually undergone the conversion. Consequently letters of inquiry were sent to appropriate contacts in Great Britain, Canada and Australia.

In general the responses indicated that problems incurred were more involved with the process than with the conversion itself. A quotation from Reference [3] summarizes the current situation in Great Britain:

"Technical problems associated with the metrication of construction were normally handled by the Metrication Working Party of the National Consultative council for the construction industry, a body drawn from all parts of the industry for which a secretariat was provided by Department of the Environment. This committee met 35 times during the four years 1968 to 1972 and produced at least 9 reports. Its main function was of course, co-ordination. It was always recognized that there would be relatively few problems facing a designer and builder working on a project that was metric from the beginning and this has been the case. The problems in general have been associated not with metrication as such but with the change to dimensionally co-ordinated standards, a change which had of course, been closely associated with metrication from the start although it is in fact a separate change. This has been revealed by the recent discovery that while more than two thirds of projects currently being handled by private architects are metric, only about $12 \%$ are dimensionally co-ordinated. Thus the problem which has probably received more attention than any other, the problem of the dimensionally co-ordinated brick, is not really a metric problem. The standard brick in the UK has been metric for at least 3 years and differs little in size from its predecessor. This has, however, proved not to be entirely suitable for certain of the requirements of dimensionally co-ordinated building and an extended program of research is at present being carried out by the brick manufacturing industry and Department of the Environment in order to assess the feasbility of the mass production of a different size."

The Australian conversion to metric is going very smoothly with problems arising principally in regard to adjusting contracts to solve costs of minor changes, amending legislation, and modifying building codes for metric use. The Australian Government passed a Metric Conversion Act which defined the units, set the law and became the principal impetus to convert. A quotation from Reference [2] lists major items needing attention:

"Standards - production of key standards at an early date is a necessity and needs to be followed by efforts to ensure that the sizes in the standards are in fact adopted.

Building Materials - it is necessary to stimulate manufacturers to provide metric materials as required, to ensure customers are adequately informed of new products and to encourage inclusion of such products in designs.

Legislation - product sizes and designs are also affected by building regulations and early attention needs to be given to these; the chance to achieve greater uniformity in this area should not be overlooked.

Contracts - suitable measures to cover the period when items may not be available in the desired units need to be agreed.

Reference Texts - a bibliography of suitable reference texts in SI should be established. 
The Canadian conversion to metric is just beginning to get underway and thus far there are no indications of any major problems.

In addition to these comments is the article written by Mr. L. J. F. Stone which is reproduced in its entirety in Appendix B. Mr. Stone provides a statement about the difficulties encountered in Great Britain's conversion to metric in the housing industry. The problems arise from legislation, program coordination and legal terminology. These items are, as has been observed before, problems not directly related to converting to metric but rather are administrative consequences of conversion.

\section{B. Construction Conference Depositions}

As shown in Appendix A the five major items of concern in order of importance to the participants in the Construction Conference of 1970 were (1) costs, (2) training, (3) standardization, (4) on-site adaptation, and (5) industry coordination. of the thirty activities where metrication might create a problem only four (\#'s 2, 3, 9, 12) were not indicated by at least one participant. This means that problems are expected to occur across a wide range of activities with varying degrees of impact. It should be noted that these responses are made by persons not actually going metric under an official program but are perceptions of problems in a hypothetical situation; although it must be added, that some companies and participants did respond with authority for they either have, or had, planned to go metric. It is assumed, however, that all responses were considered and represent a genuine expression of concern.

Any action taken by a company or individual over and above his normal operating procedures to convert to metric represents a direct or indirect cost either to himself, or eventually, to some other party. It is not surprising, therefore, that cost headed the list of problems. To some, the cost is less important than to others, but, in no case is cost expected to be prohibitive.

In the British and Australian experiences it was intended that the costs be taken where they fell, but the Australians are ameliorating conversion costs by providing certain tax deductions. There are many different kinds of costs and different ways of measuring them, and the magnitude and extent of cost factors for various segments of the housing construction industry is expected to be widely variable, but also less than anticipated in many cases.

Training was the second most frequent problem indicated, based most likely on its universal impact upon every phase of housing tectonics and administration. The British concern about training problems of the middle-aged and staunch believers in imperial units was unfounded in actual practice. This aspect of conversion to metric should present the least problem to companies, although training programs will involve minor costs.

The matter of standardization is a complex issue. It involves what the standard is, how it is developed, whether it is mandatory or voluntary, how widely it applies, the number of standard-setting organizations involved, and the direct or indirect impacts on segments of the industry. The magnitude of this situation is clearly drawn when it is realized that over 100 different sources of building standards in the United states for building construction must be brought together in a common effort to develop, approve and implement standards for the adoption of, or accommodation to, the metric system. Conversely, however, this presents a unique opportunity to achieve uniformity in building codes. The coordination of this massive undertaking would be without precedent, since those countries going metric have, by a large factor, far fewer standard-setting groups. Certainly not all parts of the 15,000 local codes in the United States would have to be changed, but changing those parts dealing with the joining of components, the joining of essentially different functional products, and required performance criteria are likely to produce delay, confusion and inconvenience if not adequately considered by the industry prior to conversion. The principal task then lies in developing the standard, obtaining industry-wide concurrence and acceptance, and assuring fairness to all parties directly or indirectly affected by the standard.

The concern about on-site adaptation to metric units and products is in regard to the expected confusion and errors stemming from unfamilarity, and the consequent waste of time and materials which might, in some cases, lead to higher costs. It is unlikely, however, that this will be a major problem or cause undue delays in converting and adjusting to metric construction practices.

Industry coordination is seen by the participants to be an essential ingredient to any program of conversion. Without it, the problems of standards, efficiency and timeliness if not properly anticipated, will probably result in chaos, disorder, 
and losses. It is in this matter of coordination and cooperation that the British are having their worst experiences. The difficulties, as of 1972 , are presented in the paper by Stone, reproduced in Appendix B.

\section{Study Sources of Information}

The information and content of this report are based in part upon direct conversations with participants of the Construction Conference of 1970; resident experts at the National Bureau of Standards; direct conversations with officials of major segments of the housing industry; direct and indirect communications with prominent officials of the metrication Boards of Canada, Great Britain and Australia; the source material listed in the bibliography; and the Libraries of Congress, American Institute of Architects and the National Association of Home Builders.

The Bibliography accompanying this report includes almost all of the essential publications dealing with the impact of metrication upon housing tectonics or containing a perception, or concept, of value pertinent to the items and issues discussed within this report. Much of the material and sources were fragmented or isolated, so this report represents a summary and exposition of the current material on the subject, in addition to its other objectives.

\section{Survey Form}

one source of information which was considered but not acted on for reasons of timing and resources, was to question those in the housing industry who would be directly confronted with the wide range or impacts of metrication. The intent of such a survey would be to have the respondent identify general descriptors of his perceived problems of metric conversion and provide a detailed description of the specific nature of each problem. The survey, in principal, would provide a distribution of activities thought to be impacted, the level at which the impact would occur and a suggested approach for resolving major problems. The success of this kind of measuring instrument is greatly dependent on a common understanding of terms, the number of responses in each category, and the amount of useful information provided. A survey form was developed as a prototype and its concept, intent and detail are discussed in section IV, Part III, subpart C. 7 .

\section{FINDINGS: PART III - STUDY RESULTS}

\section{A. Introduction}

On the pages following there is a review of the sources used in the analysis, with the results of the analysis laid out in seven sections appropriate to the subject and the conclusions drawn. The final section restates the major problem areas in summary and represents the culmination of the developed identification of impacts from the preceding evaluations of each section.

\section{B. Sources}

The sources for the evaluation of the impact of conversion upon the domestic housing industry are primarily from those given in the bibliography. Appendix A, developed from the depositions given at the Construction Conference of 1970 and collated for the purpose of this study, was used in part in the Impact Analysis which follows. Of the five references $(2,3,5,6,18)$, four are based upon foreign experience and the other from domestic studies.

\section{Results}

The results are presented in seven parts which follow. This division provides a better presentation than a non-divisional discussion, because the context of the points being made and their sources are important to a better understanding. The summary which follows this section brings the results of the sources and the analysis into a tighter perspective without the encumbrance of the underlying back-up material. The division also assists in keeping the discussion clear in relation to the subject, thus avoiding an inordinate and confusing mixture of information and conclusions.

\section{Foreign Experience}

of the three major foreign countries which have gone, or are going, metric only the British and Australian experience provided useful material.

The Australians started their program of conversion at the beginning of 1971 , with preparatory studies, intending to be fully converted to metric, in the sense of metric 
construction on new projects, by the end of 1976. Their program is in ten steps and included allied industries of gas, electricity, land and surveying, water supply, sewerage, stormwater, Dept. of Works and the Road Construction Industry. They have experienced very little difficulty so far in their conversion and indicate being on schedule. The ten steps ${ }^{1}$ are as follows:

1. TIME TAKEN TO PRODUCE PROGRAM AND GUIDELINES

2. PREPARATORY STUDIES

2.1 Decision regarding basic metric preferred sizes

2.2 Key dimensional recommendations based on users studies

3. ESSENTIAL REFERENCE PUBLICATIONS

3.1 Time required to produce essential reference material of an official nature (Building regulations, etc.)

3.2 Time required to produce essential reference material of an industrial nature (Drawing Practice Code etc.)

4. PRODUCTS WHICH REQUIRE COORDINATED PREFERRED SIZES

4. I. Time required for manufacturers to provide technical information in metric terms for their products

4.2 Time required for Standards Association to produce metric dimensional recommendations and standards for these products

4.3 Time required for manufacturers to change to full production of metric coordinated preferred product sizes

5. PRODUCTS WHICH ONLY REQUIRE SENSIBLE METRIC SIZES AND VALUES

5.1 Time required for manufacturers to provide technical information in metric terms for these products

5.2 Time required for Standards Association to produce metric standards for these products

5.3 Time required for manufacturers to change to full metric production of these products

6. PRODUCTION OF METRIC MEASURING INSTRUMENTS AND EQUIPMENT

7. EDUCATION OF PROFESSIONAL AND TECHNICAL PERSONNEL

8. CHANGE TO METRIC DESIGN AND DOCUMENTATION ON NEW PROJECTS

9. TRAINING OF CONSTRUCTION PERSONNEL

10. CHANGE TO METRIC CONSTRUCTION ON NEW PROJECTS

The problems encountered have been with accommodating costs of minor changes in contracts regarding construction, amending codes, not having a national code for the plumbing industry, and getting the legislation in step with the conversion program. All of the major segments of the industry have made, or can make, the conversion at the technical level but some business managements are cautious in making the final commitment. Business entities in Australia, as in the U.S., can claim costs of conversion as a tax deduction and so no effort to measure the national cost of metrication is being made. Reference [1], page 15, suggests that metrication will require some equipment modification and in some cases complete replacement; that plants and equipment having a weighing function will need re-calibration which can be easily accomplished; and that design aids and technical marketing literature will need revision accordingly. Since one-third of the total housing development is for the government sector the implied policy stated in "...the government sector, through various authorities, will influence decisionmaking because of its control of statutory regulations, involvement in certification of measuring instruments and equipment, and extensive research and testing activities" 2 the Government is in a strong position to encourage a rapid and efficient conversion. Other items to be given attention are: ${ }^{3}$

\footnotetext{
${ }^{1}$ Reference [1], page 20.

${ }^{2}$ Reference [1], Section 3.5.2, page 16,

${ }^{3}$ Reference [2] .
} 
Standards - production of key standards at an early date is a necessity and needs to be followed by efforts...to ensure...the standards are adopted.

Legislation - early attention needs to be given to product sizes and design which are affected by building regulations; opportunity for uniformity should not be overlooked.

Contracts - suitable measures to cover the period when items may not be available in the desired units need to be agreed.

One final quote from Reference [1] indicates the importance of cooperation: "Overseas experience has shown quite clearly that a majority of the cost of problems anticipated during the changeover do not materialize, provided that goodwill and momentum for the change are maintained."

The British experience dates from approximately 1967 when the time-table for conversion was established. Although the program is slightly behind schedule, the problems are with coordination, cooperation and legislation, and not with the conversion of the technology. From Reference [3] is an indication of this: "...the problem which has received probably more attention than any other, the problem of the dimensionally coordinated brick, is not really a metric problem. The standard brick in the U.K. has been metric for at least 3 years and differs little in size from its predecessor. This has however, proved not to be entirely suitable for certain of the requirements of dimensionally coordinated building...". The best discussion of the British experience is the paper by L. J. F. Stone, FRICS, which has been included as Appendix B. It is much too lengthy to re-state here, so the reader is referred to Appendix $B$ for a close reading. It essentially points out that legislation, codes, industry cooperation and some contract problems are the major problems of the conversion.

Although the papers by Williams and Hobbs are from 1968 their comments are particularly interesting and somewhat prophetic. From Williams' paper (Reference [5]) we give the following on different subjects: on the builder-supplier relationship "...The manufacturers of heavy industries will not make an easy change [to metric] because they have got to work out the capital costs of the equipment which they use, but the lighter industries, I think, will seize this opportunity to produce commodities to metric measurements. This will create problems for the builder because he may find that at any time of tendering [bidding] he has priced on a certain specified commodity, the dimensions of which have been converted from our present standards to metric. By the time he comes to purchase it, the manufacturer may have changed over and be producing different dimensions."; on contractual claims: "... But when he [contractor] gets a major change in his present working conditions such as this [going metric]; when he gets errors in pricing; when he gets difficulty in supply and trouble with his labor, is he going to be content to say I will not make contractual claims?"; and finally Williams, in the same paper, suggests that the contractor could well be the loser in cases when the contract was taken literally in regard to what is included or excluded.

In Reference [6], P. S. Hobbs is concerned with specifications and regulations, training, supply and demand, the cost of change, inter-relationships, manufacturer's policies and planners, functional panels and the British standards Institution. The most essential point given in Hobbs is the importance of coordination of expected performance on the part of the entities of the industry and the appearance of the necessary standards that govern their compliance. If manufacturers, designers and contractors are each controlled by separate demands or constraints, then a strict coordination of target-dates and standards is necessary to avoid an embarassment to the program.

\section{Construction conference}

This conference, held in 1970, is summarized in matrix form in Appendix A. The deposition of each participant was examined for statements on the impact of metrication particularly relevant to the domestic housing industry. From these statements and the list of activities of the industry a ranking, or correlation, can be made depicting the general feeling about perceived problems.

The top five are cost, training, standardization, on-site adaptation and industry coordination. It is difficult to ascertain after the fact of the conference what is meant by cost and how it is to be measured. The cost factor can take a wide range 
of effects and should be tempered by expected benefits from conversion over a time-frame well beyond that in which costs are of concern. Training would be a 4 th level of problem severity (see FINDINGS: PART I.C) and all experience to date indicates that training to use metric units is not a significant problem relative to the totality of possible problems and costs. Standardization is an extensive and complex problem which pervades the entire industry and requires exacting and precise planning on the part of the industry and government. On-site adaptation to the use of metric products and dimensioning, although at the heart of the construction process, does not appear to be a serious problem and is perceived as no more than of 4 th level severity. Industry coordination is of paramount importance and will be the principal concern of whatever committees are charged with the organization of a conversion program.

Several of the activities were not mentioned in the depositions but it should not be concluded they are free of possible impact.

These results should be viewed as being, at least in part, a mixture of opinion, fact, experience, bias, and in some cases, fear of change. Many problems in the British experience that were anticipated did not occur and the general experience of both the British, Australians, and other countries, found the going easier than expected.

The principal danger to a business entity is making a bad decision out of ignorance or fear. To avoid this situation is one of the obligations of the planning and coordinating process. The mechanics of conversion must provide safeguards against inequities.

\section{Legislation}

There are at least three essential changes ${ }^{l}$ to be made in legislation to facilitate the conversion to the metric system.

1) The metric units to be used need to be defined and accommodated for practical use,

2) All legislation containing references to measurements in non-metric terms will require amendment,

3) All national and local standards, particularly those required by manufacturers, should undergo early conversion.

The British experienced problems which have arisen from the absence of a legislative program, and stone indicates this condition in his enumeration of difficulties. He states that "no comprehensive list of legal units for use and incorporation in legislation had been produced before the construction industry began to change" 2 , and "a number of important legislative measures which incorporated imperial units had not been amended". He cites as specific examples ${ }^{3}$ the cases when safety criteria were defined in imperial units because the law required it, and had not been changed although metrication was underway.

\section{Contracts}

The problems facing the contractor are those of a very practical nature and directly affect his ability to function efficiently. The preparation of a contract may have to address one or more of the following: 1) the lack of supply of specified materials, 2) the capability to submit claims directly related to metrication problems, 3) the inclusion of equitable qualifying clauses directly related to metrication, and 4) proper inclusion and use of legally accepted metric terms and definitions. To these four might be added what the British call "sympathetic consideration" which deals with the resolution of snags in the work not directly covered by the contract.

These problems will probably peak during the early phases of conversion when supply and availability of metric products may be unpredictable. The question of

\footnotetext{
${ }^{1}$ Appendix B, page 22.

'Ibid, page 26.

${ }^{3}$ Appendix B, page 26 .
} 
impact depends on how rapidly manufacturers gear for conversion, how long the dual-stocks are carried by suppliers, and how well delays are anticipated.

Another problem of an operational nature is the burden placed upon the bidding process where metric is required. The contractor may have some doubts about costs, supply and delivery. These uncertain factors require either the contractor accepting a greater risk, not bidding at all if he is too uncertain, unrealistically inflating his estimate, or some reasonable accommodation of cost estimation on the part of the buyer.

\section{Construction Activities}

Pursuant to the principal objective of the study, a list of activities of the housing construction industry was drawn up to serve in the analysis of impact and identification of potential problem areas. The list, augmented with additional descriptions, has been used in Appendix A and in the analyses to follow.

Activity is used here to denote an operation or function of the housing construction process. Its form and extent depend upon the business entity in the industry and consequently has a degree of importance consonant with the role it assumes in the operations of the business entity to which it applies. There may be many activities of the housing industry not included in the list but the principal qualification for inclusion was the potential for some degree of impact or concern from converting to the metric system.

Exhibit I gives twenty-three activities and other descriptors which comprise the areas in which metrication may have an impact on operations or create a condition which requires a program or study for its resolution.

\section{Impact Analysis}

The objective of this study was to identify and describe potential major programs incurred by the domestic housing industry upon the occasion of going metric. The results of this investigation can be used to determine general policy and to foster more detailed studies of particular impacts of interest.

The analysis which follows is an evaluation of twenty-three activities for the industry as a whole. No attempt is made at this point to apply the analysis to a specific business entity of the industry although the method lends itself to this if information is available.

If the four levels of problem severity defined in Part I.C, are combined, in matrix form, with the three broad areas of operations, we obtain a useful framework for categorizing the twenty-three activities. Figure 1 depicts the matrix. By placing each activity in the matrix, a general picture of impact and distribution of activities can be obtained. The process of placing an activity is one of judgment and reliance on information from the sources. One subjective distribution is shown in Figure 2. Each activity has been placed according to the severity which seems best descriptive of its average impact and may appear in more than one combination of severity and area.

Those activities which are repeated are marked by "*". This assessment suggests that problems are predominantly technical or administrative, should not impede conversion, and costs of conversion are not expected to be significant. Applying this technique to selected business entities of the housing industry might yield different results from the industry as a whole, or from some other business entity. In Figure 2, however, each activity was placed according to its highest expected level of impact although it could occur at a lower level of severity. Activity (13), Coordinated Dimensions, appears in both the technical and administrative areas at the 2 nd level but it might, under some circumstances of business entity and areas, only impact at the 3 or 4-ievel. The placement of (21), Manufactured Products, and (22), Retooling, as severe in both the technical and economic areas indicates a recognition of the relative factor of cost to the other impacts. It may be that only a few exceptional cases of excessive costs will be experienced but in the overall scale of things, activities (21) and (22) have the greatest potential of high cost relative to the other metrication problems, and will have the greatest relative impact on the economic status of the business entity. should keep these costs at a minimum, however. proper planning of these activities two-way ranking of expected impacts. 
"Housing Industry Activities Related to Metrication"

1. On-the-job-training - training received by employee at the location of his job assignment performing specified tasks under the supervision of an authorized person.

2. Terminology - the technical or special terms or expressions used in the building crafts by manufacturers and contractors whose meanings are common to the industry and clearly understood by all who use them.

3. Relabelling - the process of modifying existing labels to show clearly and according to specifications, the metric units of the product.

4. On-Site Adaptation to Metric - the ability of a contractor to work in metric units and use or modify metric products on site in the process of housing construction.

5. Inventory Control - Administration and control of the sales and purchases of stock; and planning for the quantity, storage and distribution of stock.

6. Purchase and Sales - Direct and administrative activities dealing with the acquisition of products and materials, and the process by which products are advertised, sold and distributed to customers or market segments.

7. Standards/Specifications - a voluntary or mandatory set of rules, conditions or criteria which define the minimum performance or quality of a product under operational use.

8. Regulations/Codes - Legally imposed, mandatory conditions or criteria which must be satisfied by a product or a process.

9. Testing - To subject a product to a series of physical experiments to ascertain its quality and performance as measured against specified criteria, regulations, or standards.

10. Code Enforcer Acceptance - An attitude receptive to metric units, dimensioning and description by those persons responsible for code interpretation and enforcement.

11. Legal Terms - The use of special terms which are recognized by a court of law and defined by law, contract, regulations or statute.

12. Contracts - we wish to indicate here the general problems of claims, alternatives and substitutions that may arise during transition to the metric system which require contract modification, renegotiation or arbitration.

13. Coordinated Dimensions - the use of a standard set of dimensions for design and product manufacture in order that construction and joining is expedited. Modular coordination is the extension of this concept to large units which are assembled to produce a finished home.

14. Records - Refers principally to the documentation associated with realty, lot descriptions, etc.

15. Handbooks, Tables, Charts - Reference material used in product design, quality control, and product performance.

16. Catalog Information \& Design Aids - Product descriptions, information or data used principally by engineers and architects in the concept stage of housing.

17. Repair \& Remodelling - Maintenance of structures built of products in the customary system during and after conversion to metric.

18. General Training - General Training involves the education of all company employees in the meaning and use of the metric system of units. It implies on-site lectures, information packages and instruction.

19. Dual Inventory - Dual inventory is the carrying of the same product in both metric form and in customary form. 
20. Quality Control - Quality Control is the process of measuring product performance or manufacture against a specified standard. Quality control involves both measurement and equipment, batch rejection or acceptance and performance criteria.

21. Manufactured Products - Any product created from basic materials by a fabrication process meeting certain standards of quality control. The production is not necessarily limited to a single company and may be a composite of other products.

22. Retooling - The replacement or major modification of existing equipment necessary for product manufacture or quality control.

23. Calibration - Adjustment of existing equipment, tools or procedures to accomodate a dimensional change, a scale change, or tolerance changes. 


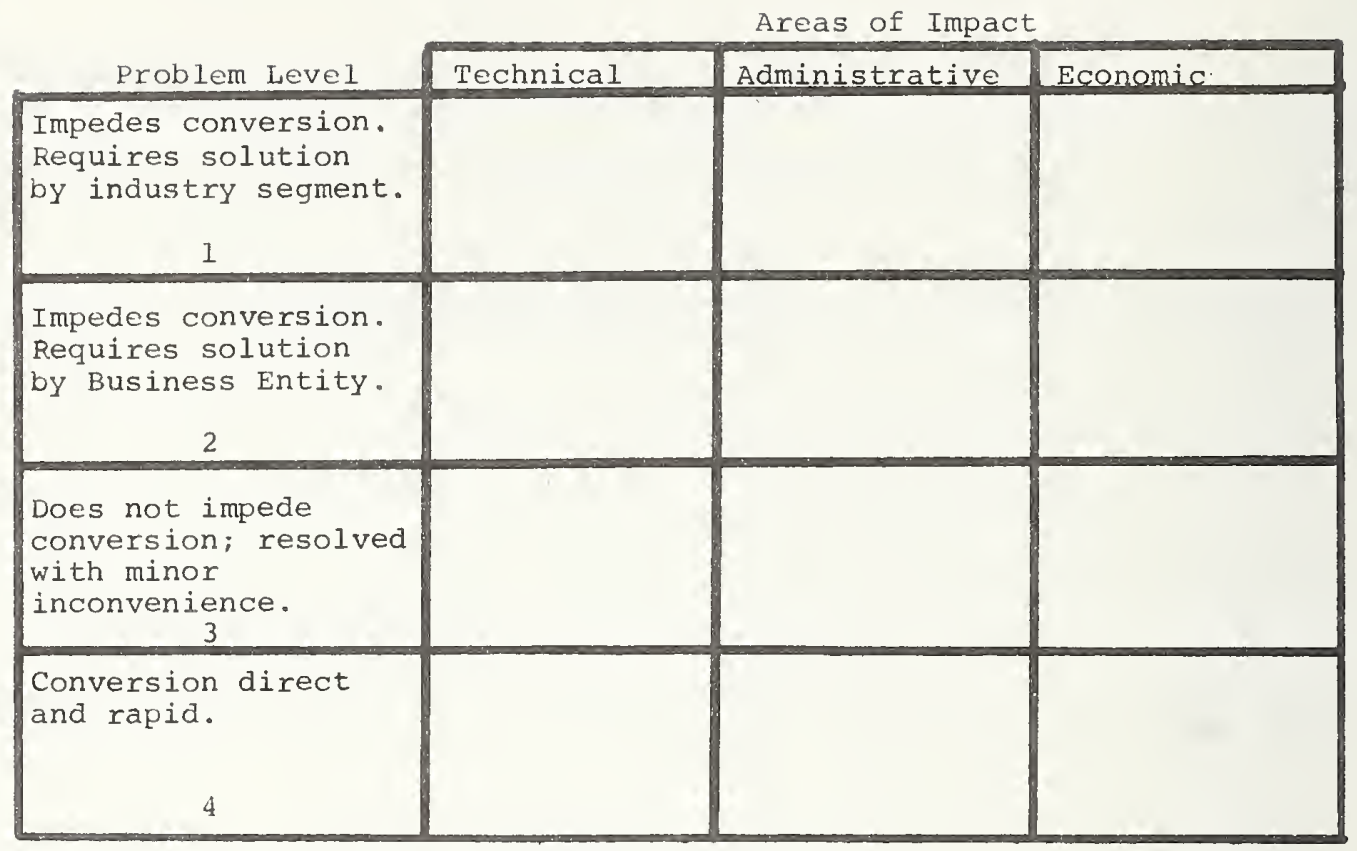

Analysis Matrix

Figure I

\begin{tabular}{|c|c|c|c|c|}
\hline Problem I & Level & Technical & Administrative & Economic \\
\hline & 1 & $(21)^{*},(22)^{*}$ & & $(21),(22)$ \\
\hline & 2 & $(13) *$ & $(5),(13),(19)^{*}$ & (19) \\
\hline & 3 & $\begin{array}{l}(9),(16) *(17) * \\
(20),(23)\end{array}$ & $(6),(7),(8),(16)$ & $(17)$ \\
\hline & 4 & $(1) *(2) *(4),(10)$ & $\begin{array}{l}(1),(2),(3),(11), \\
(12),(14),(15), \\
(18)\end{array}$ & \\
\hline
\end{tabular}

Analysis Matrix: I

*Activity appears in more Figure 2

than one box. 
Figure 3 presents the results of applying the Analysis Matrix Method to the opinions expressed by the participants of the Construction conference. In this case, the entries in the matrix are the number of participants who indicated that activity as serious enough to mention. The entry is indicated by the activity and the count; for example (15) -3 stands for 3 participants considered handbooks, tables (15) was a substantial problem area.

The results shown in Figure 4 are a further aggregation of the results shown in Figure 3: the entries in the matrix show the number of activities in the corresponding box of Figure 3, and also the total count of participant responses falling in the same box. Despite the slight skewing introduced by repeated activities in Figure 3 , the predominant effect shown in Figure 4 is that a large majority of participants considered the problems were principally technical and administrative, and occurred at the lower levels of severity. The entries in the upper right portion of the matrix indicate that, for some business entities, the costs associated with retooling and changes in manufacturing processes may be a serious problem. It should be noted, however, that there is nothing in the metrication experience of Great Britain or Australia which indicates this has yet occurred for any segment of their housing construction industry. The extent to which this might occur depends upon the coordination of the industry segment, the complexity of the product fabrication, the rate at which equipment may be economically retired and replaced, capital investment, competition, and general economic conditions.

\section{Survey}

Although not implemented in this study, a survey form was developed to ascertain the quantity and quality of data that could be obtained by sending a survey form to a representative sample of business entities in the housing industry.

The work on this survey is included to provide, for possible later use, the concept and content of the form.

The survey would be of three parts: a covering letter with pertinent questions to orient the respondent's attitude toward the desired information; a check-off of nine descriptors for each activity in which a metrication problem was perceived by the respondent; and a space on the form in which the respondent was asked to provide a written description of the principal features and details of the problem he had checked in the second part. The activities were the same as those given in Exhibit I, and were arranged in five groups for convenience. A glossary of definitions is provided as an enclosure.

The questions in the covering letter were intended to guide the respondent toward the focus and level of detail of most value in the identification of potential problems of metrication. For each activity, he was to ask himself:

1) Is there a problem?

2) What kind of problem is it?

3) Is the problem limited to the company level?

4) Does the problem involve industry-segment planning?

5) Does the problem involve industry-wide planning?

6) What solution to the problem is suggested?

7) If costs are critical, what is the nature and magnitude of the cost factors?

The respondent was then to complete the second part of the survey. The format for indicating which descriptors best characterize a perceived problem is given in Exhibit II. The activities, though not shown in the Exhibit, are entered in the left column, and the nine descriptors are divided into three areas, (1) Problems, (2) Extent, and (3) Approach, across the top of the layout. The instructions are as follows:

Instructions: In each group below are nine (9) descriptors, grouped into three (3) categories, which identify the problem type (Problem), the level at which the problem appears (Extent) and the action needed to resolve the problem (Approach). For each activity for which there is a perceived problem, please mark the descriptors in each category that best describe the problem. Mark as many descriptors as needed. A space is provided below each group for your narrative description of the special features of the problem. This information is of special importance in providing details on the conversion problem. 


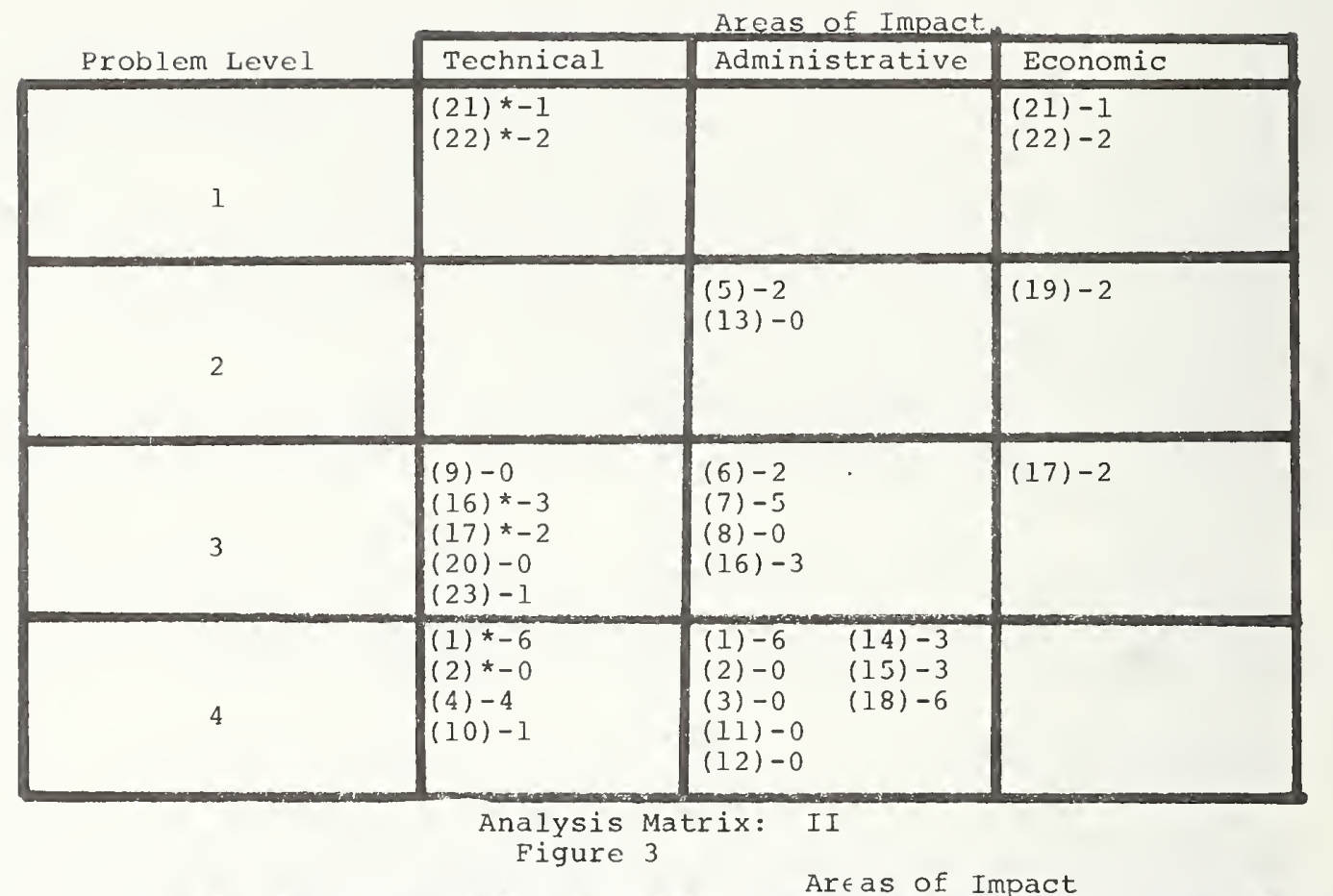

\begin{tabular}{|c|c|c|c|}
\hline Problem Level & Technical & Administrative & Ecoriomic \\
\hline 1 & $2-3$ & $0-0$ & $2-3$ \\
\hline 2 & $0-0$ & $2-2$ & $1-2$ \\
\hline 3 & $5-6$ & $4-10$ & $1-2$ \\
\hline 4 & $4-11$ & $8-18$ & $0-0$ \\
\hline
\end{tabular}

Analysis Matrix: III

Figure 4 
EXHIBIT II

FORMAT FOR ACTIVITY-PROBLEM DESCRIPTION

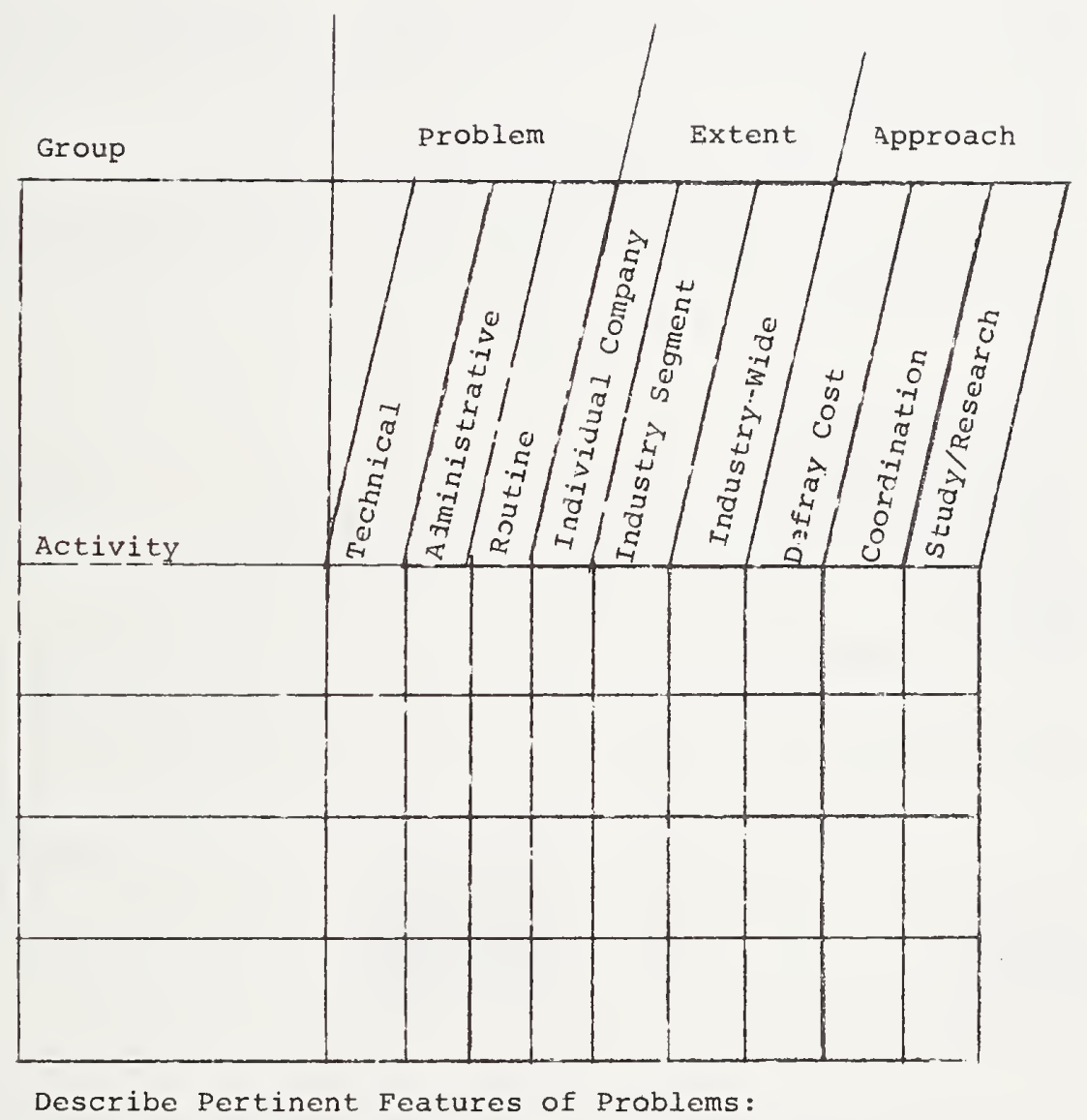


This combination of problem identification, by the use of descriptors and a written presentation of the details of the features of the perceived problem, would be expected to provide sufficient information on the impact of metrication.

Because of the current interest in Congress concerning legislation, which is expected to result in a program of metrication, it was thought that a survey was inappropriate at this time and would be of more value if executed at some later time in coordination with a national program.

\section{Summary of Results}

From the foreign experience the following were ascertained to be those problems which have emerged as causing delays and inconvenience to metrication:

1) Standards

2) Legislation

3) Contracts

4) No comprehensive list of legal units

5) Industry not properly coordinated

6) Representative bodies did not have backing of participants

7) Voluntary change produced reactions outside construction industry which affected progress

8) Inability to "think metric" causing difficulty

9) Relationship of conversion to International Standards

10) Introduction to dimensional coordination

From the construction Conference and the analysis of available information from the U.S. domestic housing construction industry the following problem areas were ascertained to be important:
1) Costs
2) Training
3) Standardization
4) On-site Adaptation
5) Industry Coordination
6) Dual-Inventory
7) Coordination of inter-dependent manufacturers
8) Legislation
9) Contracts
10) Documents
11) Repair and Remodelling

It is convenient to group these under three broad areas in order to examine their impact and resolution.

Technical

Standardization

On-Site Adaptation

Dual Inventory

Documents

Repair \& Remodelling

Training

Administrative

Economics

Standards
Coordination
Legislation
Contracts

Costs

The problems in the Technical area are closest to the business entity and likely to receive direct and immediate response. The problems in the Administrative area are more remote and involved, and bring the business entity into contact with negotiations, representative groups, problems of coordination and standardization, and with the scope of governmental activities and interest. The third area, Economics, is under his control only to the extent of his participation and coordination with industry segments, perception of his losses or gains based on alternative plans for conversion, and the impact of metrication on the emergence or genesis of a transitional market.

In conclusion, the major problems of metrication in the U.S. domestic housing industry are summarized as follows. Where it applies, equipment replacement and/or fabrication changes are the most severe impacts of metrication. The next most critical areas are those included in Federal and local governmental legislation, code changes, standards redefinition and contract qualifications. Close upon these are the coordination and planning needed within industry segments for metrication, which is 
necessary not only for a meaningful progression toward full and effective conversion but also to provide a framework for guidance and time-horizons for business entities within segments of the industry. 


\title{
APPENDIX A
}

\author{
Summary Analysis of 1970 \\ Construction Conference \\ U. S. Metric study
}

This appendix summarizes parts of the information obtained from the National Metric Study Conference -- Construction Industry, held October 1970. Although the subjects covered by this conference were not restricted to the domestic housing industry most of the participants had either a direct or indirect relationship with the domestic housing industry.

The conference was divided into six sessions over a two-day period. Session One dealt with Building Design, Codes and Standards, Session Two with Building Material Production, Sessions Three and Four with General Contractors and Subcontractors, and Sessions Five and Six with Home Builders and Land Service.

A questionnaire was submitted to the participants prior to the convening of the Conference in which they were requested to identify and comment upon the problems expected upon going metric. One of the tasks of this study was to examine the content of these responses to this question and present a summary of impacts as perceived by these representatives of the industry. The original depositions are in the library of the Metric Information office, Engineering and Product Standards Division, Institute for Applied Technology, NBS.

The summary is presented in the following Figure 5. Across the top of the matrix are the participants in the Conference and in the left hand column are listed thirty activities from which may evolve some major problem of conversion. An. "X" has been entered opposite those activities the participant viewed as being a source of delay, cost or major concern if conversion is undertaken within the aegis of an official national program of metrication.

The following points of interest about this data are (1) the top five problems concern cost, training, standardization, on-site adaptation and industry coordination, in that order; (2) no participant remarked about possible contract problems (activity No. 12) but this is one of the major problems in the British experience, and (3) the cost of going metric is thought by some to be prohibitive and the benefits marginal.

The British experience with contract problems is addressed in Appendix B and forecasted by Williams in Reference 5. 


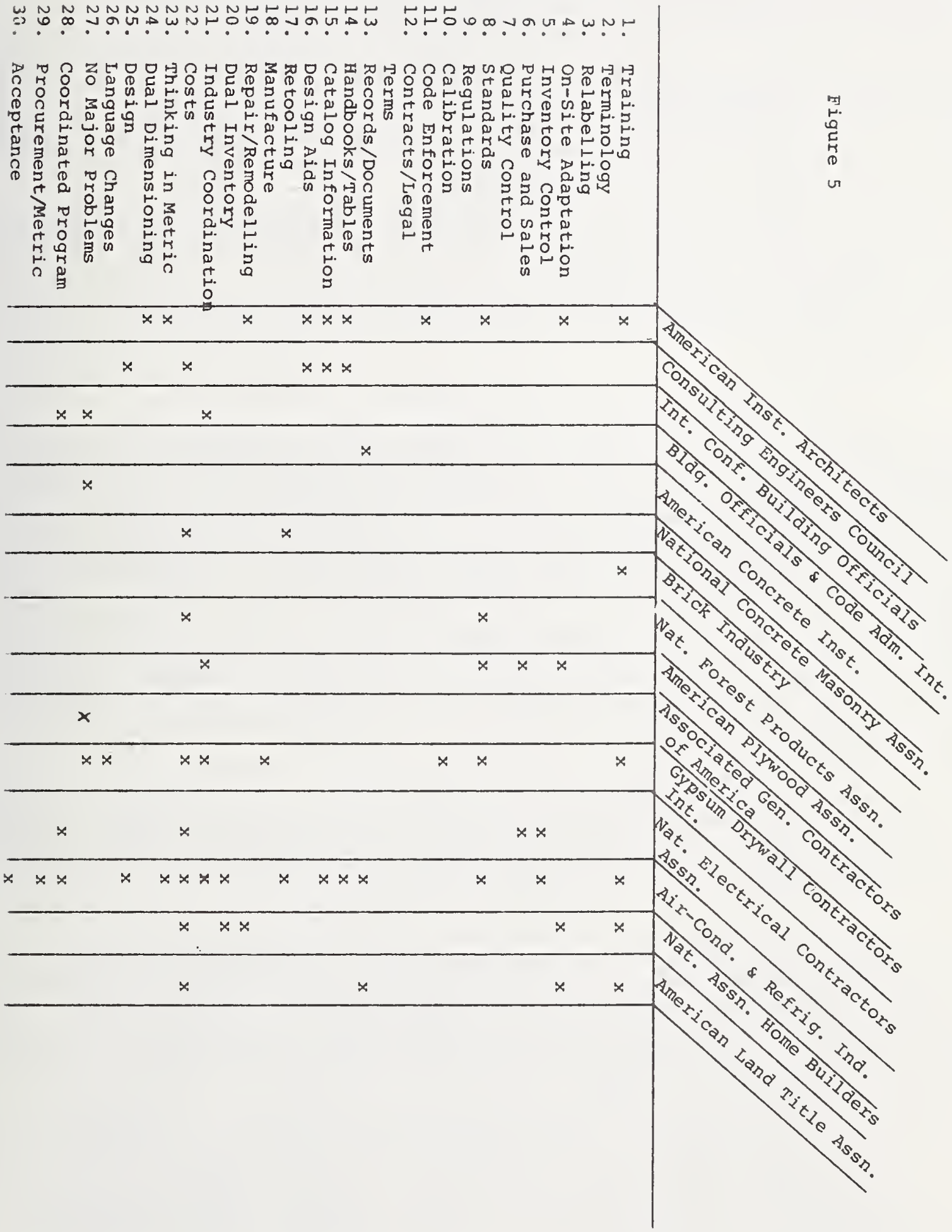


In May 1965, the Government announced that it had been impressed by the case presented by representatives of industry for the wider use of the metric system of weights and measures: the Government moreover considered it desirable that British industries on a broadening front should adopt the metric system, sector by sector, so that it could become in time the primary system of weights and measures for the country as a whole. The intention was to support and encourage the change in industry by for example arranging that tenders for procurement by the Government and other public authorities should be in terms of metric specifications as and when this became practicable for particular industries.

The Government subsequently appointed a Standing Joint Comittee to co-ordinate its own and industry's policies on metrication. In its report made in July, 1968, this Committee made three main recommendations:

(1) that manufacturing industry could make the change efficiently and economically only if the economy as a whole moved in the same direction on a broady similar time-scale and in an orderly way;

(2) that a Metrication Board should be established to guide, stimulate and co-ordinate the planning for the transition for the various sectors of the economy and

(3) that any legal barriers to the use of the metric system for all purposes within the United Kingdom should be removed.

The Government accepted the Committee's recommendations, but made it clear that no compulsory powers to impose metrication would be sought; that there could be no question of compensation and that the costs of metrication must lie where they fall; that the Government would not be committed to endorse the programme for any sector of the economy before final proposals for that sector had been submitted; and that further consultation would be needed on the timing of legislation. The Government also accepted the end of 1975 as the target date for all provisional programmes with the qualification that if this date were to prove unreasonable for any particular sector, the programme could aim at an earlier or later date.

What the change Involves for a country with a Legal System Based on Imperial Units.

It is perhaps worthwhile to consider at this point what a change to the metric system involves for countries whose legal systems of measurement are based on other units - - for example on the imperial system as in Britain and in many countries of the commonwealth. In most countries there will be at least three essential features of the changeover:

(1) the introduction of legislation listing and defining the metric units to be used. The metric system has been lawful for most purposes in Britain for over 70 years, and it has consequently been possible to make considerable progress with the changeover without such legislation. Nevertheless, a need exists to re-define and extend the range of authorised metric units, and appropriate legislation will have to be introduced in due course:

(2) the amendment of all legislation containing references to measurement in nonmetric units. Since Britain's primary system of measurement has been the imperial system, it is not surprising that the references to measurement in the great mass of our legislation are in imperial terms. Although all such legislation must obviously be amended before Britain becomes a truly metric country, in relatively few cases does it significantly inhibit the change, since statutory requirements expressed in imperial terms can usually still be met by those working in the metric system, and

(3) the metrication of national standards, in particular those required by manufacturing industry for metric production of materials and components. In Britain this work has been recognised as the most vital and essential feature of the metric change. Prior to the setting up of the Metrication Board, the British Standards Institution (our equivalent of the National Bureau of Standards) was also the focal point for the planning of the metrication of industry. These standards will be referred to in more detail in later parts of this article. 
Perhaps the most important feature of the fundamental change involving metrication is the need for integrated planning. Some changes are completely dependent upon other decisions and some industries are so involved with others that the two must be planned to change in unison. Specific examples of these are national standards which cannot be revised in advance of the introduction of new legal units and sectors of industry, such as construction and mechanical and electrical engineering, which are inter-related.

Even within particular sectors there is a need to programme the changes of the component parts. The construction industry, for example, comprises (a) the design professions, (b) the regulation makers, (c) the construction agencies and (d) the material producers and suppliers. No one of these component parts can make an effective change in isolation or out of phase with the others.

An added complication is that very few, if any, sectors of industry, however specialised, operate in isolation from the public consumer sector, and any attempt to change industry separately from the consumer sector is bound to create some confusion and breed opposition. The reaction of the construction worker who is required to spend his working day measuring in metres and kilogrammes and then does his domestic shopping in yards and pounds is predictable and understandable. The absence of an integrated programme in the UK has had a marked effect on the smoothness and progress of the change in the construction industry, and this aspect will be discussed later in this article.

\section{The Structure of the Construction Industry}

The above discussion gives an indication of the situation facing the construction industry when it made its decision to be among the first to change to the metric system of measurement. The size and structure of the industry is such that it faced no easy task. It can be divided broadly into three sectors-design, the manufacture of components and materials, and building and civil engineering works. It is dependent on other industries for supplies of such materials as steel, glass, plastics and timber, for which the construction industry is not by any means the main customer. With an annual output in the region of $\$ 4,500$ million (approximately $\$ 9,000$ million), the building and civil engineering sector of the industry consists of some 80,000 firms, employing more than 1 million operatives. Only 23,000 of these firms employ more than seven workers, and only 500 employ 500 or more. Approximately one third of the output is on building maintenance and repairs, and the public sector, including the local authorities and nationalised industries, account for more than 50 percent of the overail expenditure.

What "going metric" means in the UK

Changing to metric is not just a question of substituting metric units for their imperial equivalents. In the first place, there are a number of metric technical units such as kilogramme force which have been used for some time throughout the world, and some of these which are not in the International System (SI) have considerable support, particularly in the engineering field. As almost all of the major metric countries have adopted or will eventually be adopting the International System the UK decided at the outset that it would adopt SI units as the basis of its new system of weights and measures.

For some years prior to the decision to change to the metric system, a comparative small group of people had tried to introduce the four inch module as the basis of building and civil engineering design. Despite the strenuous efforts of the Modular Society to promote this nationalisation lack of interest and incentive prevented its adoption. The change to the metric system was seen as the golden opportunity to provide the incentive and interest to rationalisation, and the construction industry therefore decided to introduce dimensional co-ordination simultaneously with metric units. Dimensional coordination, in its simplest terms, is the adoption of a very restricted number of increments or modules for the dimensions of buildings and for the sizes of materials and components which go into them. In the UK these increments or modules are:

$\begin{array}{lr}\text { first preference } & 300 \mathrm{~mm} \\ \text { second preference } & 100 \mathrm{~mm} \\ \text { third preference } & 50 \mathrm{~mm} \\ \text { fourth preference } & 25 \mathrm{~mm}\end{array}$

The third and fourth preferences are generally applicable only to dimensions or sizes which are less than $300 \mathrm{~mm}$. 
The introduction of dimensional comordination into design is not mandatory, but as all head standards and many others produced by the British standards Institution and the new sizes of almost all major components and materials are based on the preferred increments, the acceptance of this discipline will be widespread throughout the industry. The public sector, which controls approximately half of the input to the building industry in the UK, has given added impetus to the introduction of dimensional co-ordination by making this discipline mandatory for the design of its new buildings.

It may not have been fully realised either by industry or the Government that a change to the metric system of measurement would automatically provide opportunities for other reforms which, although giving rise to short term complications, would be seized upon by industry as spin-off benefits. The most far reaching of these was the opportunity to rationalise sizes and weights of commodities and, in so doing, reducing drastically the variety of sizes and weights being manufactured and stocked under the existing system. Very few imperial product sizes have reasonable metric equivalents. The metric equivalent to twelve inches is $304.8 \mathrm{~mm}$ which obviously cannot be used with any facility. Similarly one pound is equal to $0.4536 \mathrm{kilogrammes.} \mathrm{In} \mathrm{practice,}$ therefore, the original twelve inch size is likely to be reduced to $300 \mathrm{~mm}$ and the one pound package to become $0.5 \mathrm{kilogrammes}(500$ grammes). The next logical step is to rationalize in ranges so that the weights of consumer goods may be standardised as, for example, $125,500,750$ and 1,000 grammes.

This process of rationalisation is being actively encouraged by the International Standards organisation (ISO) and has become a most important factor in the change. as follows:

Metrication in the construction industry in the UK can therefore be summarised

(1) the adoption of SI as the system of weights and measures:

(2) the adoption of the technique of dimensional co-ordination and

(3) the rationalisation of the sizes of components which are not significant

to dimensional co-ordination.

Progress to Date

The British Standards Institution's Building Divisional Council took the first step along the road to metrication when it set up the Metric Panel (Construction Industry) B/-/9 in May 1965 under the chairmanship of a Director of one of the largest contracting firms in the industry. Some firms were more anxious to begin the change to the metric system than others, but since the various sectors of the industry are so closely related, it was considered essential that the change should be carefully coordinated and implemented in a systematic way. After investigating the implications of metricating construction work, therefore, the Metric Panel was charged with the major task of preparing a programme for the changeover with the co-operation of the industry as a whole. The programme was published by the British Standards Institution in February 1967. Its main provisions were:

(1) essential reference publications to be available in metric terms by the end of 1968 ;

(2) the change to metric design of construction projects to begin in 1969 and to be substantially complete by the end of 1971:

(3) the change to metric construction on site to begin in 1970 and to be substantially complete by the end of 1972 ;

(4) the production of metric standards by the British standards Institution to begin in 1968 and to be substantially complete by the end of 1972;

(5) the changeover to production of materials and components designed to metric standards to begin in 1970 and to be substantially complete by the end of 1972 .

Two other bodies were found to facilitate metrication of construction work. The first of these was the Working Party on Metrication which was set up by the National Consultative Council of the Building Civil Engineering Industries in May 1968 with the task of keeping under review the progress of metrication, identifying obstacles to the accomplishment of the agreed programme and making proposals for overcoming them. The Working Party is chaired by a prominent member of the construction industry, and consists in the main of representatives of design, manufacturing, and contracting interests. The second body was the Metrication Board's Steering Committee for the Industrial Materials and Construction Industries which has concerned itself primarily with coordinating the metrication programme of the various sectors of industry with which it is concerned, so as to ensure that progress in one sector is not impeded by lack of progress in another. 
With only about a year to go before the construction industry is due under its programme to substantially complete the change to metric units of measurement, progress to date inspires confidence that it will achieve its aim. The following is a summary of the present position.

standards

The British Standards Institution identified 466 standards and codes of practice which would eventually need to be metricated. Of these, only 125 standards and 34 codes of practice were considered vital to the construction industry's metrication programme, and the metric versions of the greater number of these have either already been published or are approaching the publication stage. Work on the remainder is being given priority.

\section{Project Design}

At the construction industry's request, the public sector set the pace by designing as much new work as possible in metric from the beginning of 1969. By the middle of 1971, public sector work to the value of $f 3,000$ million had reached the drawing board, and work to the value off 900 million will have started on site by the end of the year - most of the remainder will have reached the sites by the end of 1973. These results were achieved by each government department specifying dates from which all new work, whether designed within the Department, by local authorities, or by private consultants, must be in metric units. The department responsible for public sector housing, for example, issued instructions that all schemes submitted for approval at the tender stage after 1 January 1972 must be designed in metric dimensions; all new school projects started on site after 31 March 1972 are in metric, as will all hospital schemes starting after 31 December 1972; the first metric contracts for public highways were placed in 1970, and all new trunk roads and principal road designs will be fully metricated by 1973; virtually al1 other new works for government departments, defense establishments, etc. have been designed in metric since early 1969, and even maintenance work in this field is almost fully metricated. The private sector of the industry has been somewhat slower off the mark, to the extent that, by the middle of 1971, the value of work being designed in metric dimensions totalled only 320 million. This was, however, to be expected; designers of private sector projects serve a multiplicity of clients, few of whom have any particular interest in the long term benefits which the construction industry expects to derive from metrication, and they therefore see no advantage in having their projects, most of which are relatively small in scale, designed in unfamiliar metric measurements. Nevertheless, the Royal Institute of British Architects remains firmly committed to the metrication programme, and its attempts to persuade its members to design as much new work as possible in metric have met with some success. Up to the end of September 1970, the value of private sector projects being designed to metric dimensions was only $\mathrm{fl}^{29} \mathrm{million}$ or 11.5 percent of the total design workload. In the last quarter of 1970, however, the proportion of projects reaching the production drawing stage which were in metric dimensions rose to seventeen percent of the total. In the first quarter of 1971 , the proportion rose further to 24 percent and in the second quarter to 28 percent. If this accelerating trend towards metric design continues, there is little doubt that the private sector will soon make up the lost ground.

Training

Training has perhaps been one of the most important elements in the change process. The Construction Industry Training Board accepted a special responsibility for the contracting sector of the industry and produced an administrative guide to the metrication learning texts suitable for employers and operatives. Over 900,000 of these learning texts and other teaching aids have been distributed. The former Ministry of Public Building and Works, now part of the Department of the Environment, is directly responsible for the execution of a large construction programme for Government Departments, etc., and had, therefore, to institute a comprehensive training programme for its designers, technicians and operatives. To help the construction industry in general, it put on saie, through Her Majesty's stationery office, modified versions of its training material in four publications under the general title Metrication in the Construction Industry. The former Ministry of Housing and Local Government and the National Building Agency have each produced a series of publications giving guidance on metric house building for public authorities, architects, and builders. The National Building Agency has also organised training seminars throughout the UK attended by 3,000 professional people in the industry. The professional institutions and trade associations have also played a vital part in providing their members with information and guidance on metrication questions. 
Substantial progress has been made with the metrication of building materials and components. Bricks, partition blocks, timber, paving slabs, ceramic tiles, sanitary fitments, kitchen fittings, copper tubes, door sets, window frames, plaster board, sheet and strip, threaded fasteners, glass, plastic sheeting and reinforcement rods, are among the many items now readily available in metric, and the the trade associations concerned have firm plans for the production, to metric designs, of the remaining materials and components.

\section{Difficulties}

A number of the major difficulties which have been experienced can be said to emanate from the decision of the Government not to introduce the metric system compulsorily as the national system of weights and measures. The case for a compulsory or voluntary national change may be arguable, but there is no doubt that the absence of a legislative programme for the change across the whole spectrum of the economy has produced problems and difficulties. This article is intended to set out the experience of the construction industry in the UK and therefore deals with the difficulties encountered on a factual basis leaving the reader to draw his own conclusion. The major difficulties and the reasons for them were as follows:

(1) No comprehensive list of legal units for use and incorporation in legislation had been produced before the construction industry began to change. Earlier sections of this article have explained that some metric units were legal in the uK side by side with imperial units, but the list was not comprehensive, and the units were in the main base units. The selection of particular multiples or sub-multiples for use in specific cases were not provided for. An example of this is the unit for pressure or stress. The metre, kilogramme and second were legal units, but the definition of the second was not that which is used in the SI system. The Newton which is derived from these three units was not specified as a legal unit and neither was the bar which is in common use in metric countries. There was therefore the choice of the $\mathrm{N} / \mathrm{m}^{2}$ (now named the pascal) or the bar as the unit to be adopted for fluid or gas pressure or for solid stresses and until a decision was made, it was not possible to change legislation relating to the calibration of pressure gauges used in boiler houses and the like. As a point of interest, the legislation has not yet been amended, although the bar is now the recommended unit for fluid and gas pressures. Some small sectors are still continuing against all advice to use such units as kilogramme force.

Although West Germany is traditionally a metric country, it was not using the international system exclusively. In 1970 it decided to change to SI as its legal system over the next ten years. It has since produced and passed through its legislative system a comprehensive list of units which will be used throughout the country. As sections of the economy change, they will be required to adopt only these units. Many of our initial difficulties could have been avoided by similar action.

(2) A number of important legislative measures which incorporated imperial units had not been amended.

Mention has been made of the decision of Government to support and encourage industry in the change and to remove legal barriers. These legal barriers comprise several thousand acts and regulations containing specific requirements expressed in imperial units. The task of identifying all such legislation is considerable, and much still remains to be done. There are, however, comparatively few acts and regulations which are significant. None of these were amended before or at the time of the decision to support industry, and the change of Administration in 1971 has produced further delays with the result that, at this late stage, with the exception of pharmaceutical provisions, no primary and very little subordinate legislation has been amended. Those industries which are at an advanced stage of change are now being embarrassed, and possibly somewhat deterred, by the absence of this legislation -- to which further reference will be made.

Specific examples of these difficulties are to be found in cases where safety measures include criteria such as maximum pressures or loadings in terms of imperial units. Although designers are being encouraged to calculate in SI units, the safety factors still have to be expressed in the imperial terms required by the existing law. 
The programe for the change in the construction industry extended from January 1966 to December 1972. The programmes for the engineering industry and electrical industry extended from January 1967 to December 1975 and from January 1968 to December 1976 respectively. Many aspects of the changes in these three industries were interactive and interdependent, but the programmes were not fully co-ordinated, with the result that buildings could be designed in metric units, but some of the services were being designed in imperial units and the results converted to metric dimensions.

The lack of co-ordination in the programmes also produced a "chicken and egg" situation for designers who had to choose between designing in metric units before components in this measure were available or waiting for component information before commencing to design in metric. It would have been very helpful if a definite date had been laid down for the production of product information in metric units.

(4) Representative bodies who decided upon a voluntary change for their particular industries or sectors of industry did not have the backing of the numerous smaller companies.

The represenative bodies in the construction industry are largely composed of members of the larger or leading companies, and a graac number of small companies and individuals have expressed strong disagreement with the decision and have complained that they were not sufficiently represented or consulted. This is inevitable in a democratic society where the change is voluntary, but the aggrieved members of the community are unlikely to co-operate willingly and this can create difficulties and delays in putting the change into operation throughout the industry.

(5) A voluntary change produced reactions outside the construction industry which affected the progress of the change in the industry itself.

Although the voluntary change in industry had been progressing for some time, it was not until october 1970 that full debates took place in the two houses of parliament. A comparatively small number of members opposed the change mainly on the grounds that parliament and the public had not been fully consulted. There was little criticism of industry's decision to change to the metric system but considerable opposition to abandoning the traditional units of the pint of for such commodities as beer and milk and the mile for speed limits. Despite reassuring statements by Ministers, this sudden reaction in parliament created uncertainty in the construction industry and a temporary loss of enthusiasm which is requiring some effort to overcome. The industry, in common with some others, is now feeling the effects of the political situation. The present Administration has a small majority and a programme of important but contentious legislation ahead of it. Conservative members who are opposed to membership in the European Economic Community are generally opposed also to metrication, and the political implications of introducing legislation to make the metric system mandatory even in restricted areas of the economy at this time are obvious. This highlights the critical relationship between industry and the consumer sector in ensuring a smooth transition. The UK may well be faced with a transitional period during which industry will be adopting the metric system and feeding its products in this measure to a consumer sector which is not committed to using the new units. Failure to educate the public on the advantage of metrication has undoubtedly led to uninformed and unwarranted criticism and resistance to the change in some sectors of the UK.

The difficulties which arose from the decision to allow the various sectors of industry to make a voluntary change should not be overemphasised, but the point which is being made is that a change as fundamental as the revision of a country's system of weights and measures needs to be planned and timed in a logical and comprehensive way if delays, difficulties, uncertainty and confusion are to be reduced to an absolute minimum. Freedom of choice of the basis and timing of this type of change even when encouraged and supported by Governemnt, must inevitably lead to a more protracted transitional period during which both imperial and metric units are in use and could well perpetuate the use of both systems in some areas of commerce. Democracy without discipline is likely to produce anarchy and in any change so far reaching as a change in a country's system of weights and measures, there must be discipline. The logical sequence of events would seem to be:

(1) government to legislate for the change;

(2) government to prepare and legalise a comprehensive list of units as its system

of weights and measures and their notation;

(3) identification of all legislation and regulations needing amendment and the appropriate action for their amendment; 
(4) identification of educational changes needed, and

(5) production of a programme for the amendment of legislation and for the changes in the various sectors of industry, commerce, the consumer sector and education. This programme would be worked out in collaboration with industry, but the final decisions on timing should be taken by a central programming authority whose ultimate programme would be the most economic and least disruptive solution possible, with each part of the change occurring in a proper sequence. All sectors would then be required to conform to this final programme.

There were also difficulties which did not emanate from the voluntary nature of the change. The more important of these were:

(1) The inability to think metric in the same way as we think imperial, or in other words, the loss of a sense of value or "instinct of error", is undoubtedly causing the greatest difficulty to those involved in the change.

Experienced technologists and technicians have over their years of working with sizes and units developed a sense of values which they apply instinctively without calculation. For example, a civil engineer will remember floor loadings expressed in pound force per square foot to the extent that he can immediately recognise a significiant error in calculation or specification. When these criteria are expressed in terms of SI, particularly if more than one base unit is involved, the values are so dissimilar that errors, or for that matter, acceptable standards are unrecognisable. Designers have needed to learn a number of criteria relating to the work which they do which will act as key recognition factors and enable them to appreciate the significance of values. Using the same example of floor loadings, a civil engineer needs to memorise a selection of loadings which he uses in everyday work expressed in terms of $\mathrm{kN} / \mathrm{m}^{2}$. This selection will provide key recognition factors which he can use as "yardsticks" to recreate his sense of values. These should. not be memorised as equivalent values but as criteria related to physical conditions with which he is familiar. If, for instance, he is primarily concerned with office buildings, he should fix on the floor loading for this type of building - approximately $3.5 \mathrm{kN} / \mathrm{m}^{2}$ combined load and judge other types of buildings by comparison.

The ability to think metric can be achieved by a positive effort based on an analysis of one's thought processes when appraising sizes and values. A short article on this subject has been written by the author under the obvious title "Think Metric."

(2) The relationship of standards adopted by the UK with international standards.

It has been mentioned earlier in this article that the change to the metric system created the atmosphere for rationalisation. In many cases this could not safely be undertaken unilaterally, as international standards for the particular components or commodities were under consideration by the International Organisation for Standards (ISO). Asbestos cement products are a case in point. It is sensible to base national standards upon international standards where these exist, and work on this particular British standard was delayed pending the outcome of deliberations of the Iso. Fortunately, these difficulties have not unduly affected the progress of the change, but they are worthy of mention if only as a warning to countries yet to make arrangements for changing to the metric system of measurement.

(3) The introduction of dimensional co-ordination as an integral part of metrication.

The difference in the structure and units of the Imperial and International systems made some degree of rationalisation inevitable, but dimensional co-ordination is very much more than rationalisation. It is intended to be a systematic method and discipline of design which will determine not only the basic sizes of components, but the ranges of sizes and interrelation with other components. At the time of the decision of the industry to change to the metric system, dimensional co-ordination was little more than a basic theory, but the opportunity to reduce the variety of standards and one-off component designs and sizes could not be missed. Dimensional co-ordination was therefore introduced in the very early stages of development. Very few people understood even the basic theory, and the most that could be expected of designers in the early days was adherence to a broad dimensional discipline which would encourage the production and use of co-ordinated sizes of components. This was done 
in the public sector, but the designers had to specify available components, which were generally to imperial standards, and this in itself produced difficulties for them. In the meantime, manufacturers were moving over to dimensionally co-ordinated sizes of products and many of these are becoming available as the early metric designs reach the construction stage. We are therefore faced with a situation where components to imperial standards and sizes are being ordered for current metric projects when manufacturers are attempting to cease production of these in favour of metric dimensionally co-ordinated products for which there is as yet little demand. Although the introduction of dimensional co-ordination has added to the difficulties, it has not of itself created them. Unlike currency, a change of system of measurement cannot be made over-night. No country has

produced a programme for the change to metric with a timescale of less than ten years. There can be shorter periods within such programmes for individual industries but unless only one material is involved, these shorter periods will be of several years duration.

It is therefore inevitable that there will be a considerable period during which the construction industry will be using both imperial and metric units and will be demanding both imperial and metric components. During the changeover period contracts will be affected whether they are primarily imperial or metric. The contract can normally only specify materials and components in the terms in which they are available at the time of placing the contract which means that for a time, both imperial and metric contracts will incorporate imperial components. As these are phased out, it will be necessary to substitute the new metric components and if these are different in size, difficulties will arise. Despite this, industry will be well advised to phase out the imperial as soon as practicable -- otherwise the demand for it will continue side by side with metric and will prolong the period of dual production.

The benefits to be obtained

The reader of this article may by now have serious doubts whether the problems and difficulties of the change are really worth it, and let me say without hesitation that I appreciate not only this view but the difficulty of demonstrating to people faced with such an exercise the benefits which are likely to accrue to them.

Import/export considerations are of relatively small importance to the construction industries in most countries, since the size and weight of prefabricated building components inhibit transport over long distances, and they are in general designed specifically for their countries of origin. Construction industries who are getting along very well with non-metric units therefore tend to see little advantage in adopting another country's system of measurement.

The construction industry must however see itself as part of the whole economy rather than in isolation, and although it will as an industry obtain benefits, the major advantages will be obtained in the wider field of commerce and many of them are supplementary to the actual change of units of weights and measures.

Benefits will be derived from the system itself. The case of calculating in a system as coherent as SI with only one multiple -- ten - - has to be experienced to be believed. Once engineers and surveyors have accustomed themselves to the system, they do not want to use any other. calculating machines are programmed in decimals and every sophisticated machine must convert imperial units to decimal before making the calculation and then re-convert the result, an operation which is entirely eliminated when using the metric system. Not only is the system easy to use, it is much easier to learn than other systems, and the saving in teaching time can be devoted to other subjects producing greater benefit. No country which has adopted the system has ever discarded it.

The adoption of the system is now almost worldwide, and the benefits of standards, values and technology expressed in universal terms cannot be over-emphasised. This has been true of science for generations and the results are there for all to see. Similar benefits will accrue to industry and particularly the engineering element of the construction industry. These are real benefits, but perhaps the most tangible benefit, and one which to my mind justifies the whole operation, is the opportunity it presents to 
review and rationalize our procedures and products. The ISO is actively engaged in producing rationalized standards for international use. They are all in metric terms and will provide the backcloth to the work of all other countries. If these countries adopt international standards there will be complete interchangeability between the components produced by individual countries. Such items as electrical conduit and fittings will have standard sizes, screw thread, centres of fixing holes and the like. Building and engineering components will generally be rationalised on the basis of the international module of $100 \mathrm{~mm}$. This will mean that standard designs and specifications in any one country will meet the dimensional requirements of another, leaving only national performance requirements to be considered. If designers and manufacturers will take advantage of the opportunity for rationalization presented by the change, they can obtain real benefits.

It must be appreciated that at this time there has, as with any fundamental change, been ample opportunity to discover the difficulties. The benefits have yet to be reaped. It has therefore been possible to write at some length on the difficulties and the lessons learned. The potential benefits can only be assessed on the basis of limited experience but what must be borne in mind is that the difficulties are transient, the benefits real and substantial.

Those benefits which I have mentioned may not appear to justify the inconvenience but after four years hard experience of all of the frustrations, difficulties, disappointments and even successes, I am still as enthusiastic and convinced that the metric system with its associated implications presents immense opportunities for advancement in the construction industry. There is however one proviso. The whole operation can be frustrated or at least made unnecessarily difficult unless it is planned as an integral part of a wider operation which spans the whole economic and commercial community. Within such a concept, the construction industry can be what it is in this country -a front runner-- but unless the activities of other sectors are co-ordinated, it could well finish up by being out on a limb.

\section{Acknowledgement}

I would like to acknowledge the assistance I have had from Mr. C. A. Cooper of the Metric Office of the Department of the Environment in writing this article. 
1. Metric Handbook, SAA MH1-1972, Metric Conversion In Building and Construction, Metric Conversion Board, Standards Association of Australia, 1972.

2. Letter, P. J. O'Neill, Senior Project Office, Metric Conversion Board, Australia; May, 1973.

3. Letter, P. J. Stroud, Metrication Board, Great Britain; June 73.

4. Metric Housing - The Transitional Period, The National Building Agency, Sfb Ba4: (98) UDC 721.013; October, 1968 .

5. Williams, T. G., Going Metric From the Contractor's Point of View, "Municipal Building Management," 2 , 14-24, 1968.

6. Hobbs, P. S., Change to Metric-Viewpoint of the Manufacturer, "Municipal Building Management", $2,44-49,1968$.

7. Pfeiffenberger, L. and J. La Pine, Think Metric, paper, March, 1972.

8. The BOCA Basic Building Code, Fifth Edition, Building Officials and Code Administrators International, Inc., 1970.

9. U. S. Metric Study Interim Report, Testimony of Nationally Representative Groups, NBS SP 345-12, July, 1971 .

10. Construction Review, Annual Statistical Issue, Monthly Data 1967-72, Dec. 1972.

11. Construction Review, Monthly Industry Report, Construction's Input-Output Profile, August, 1970.

12. Construction Review, Monthly Industry Report, Construction in Japan, November, 1972.

13. Going Metric in the Construction Industry: Why and When, Ministry of Public Building and Works, London: Her Majesty's Stationery Office, 1967.

14. Going Metric: The First 5 Years, 1965-69; The first report of the Metrication Board 1970 (Great Britain).

15. Report to the Congress: A Metric America - A Decision Whose Time Has Come, Dept. of Commerce, NBS SP 345, July, 1971.

16. Metric Conversion For Australia, Metric Conversion Board, Australian Government Publishing Service, 1971.

17. Orientation For Company Metric Studies, Metric Advisory Committee, ANSI, 2nd Edition; March, 1970 .

18. Stone, Leslie J. F., FRICS, In Britian They've - "thought metric", The Building official and Code Administrator, pp. 10-17, May, 1972.

19. U. S. Metric Study Interim Report, Nonmanufacturing Businesses, NBS SP 345-5, July 1971. 

NBS.114A (REEV. 7.73)

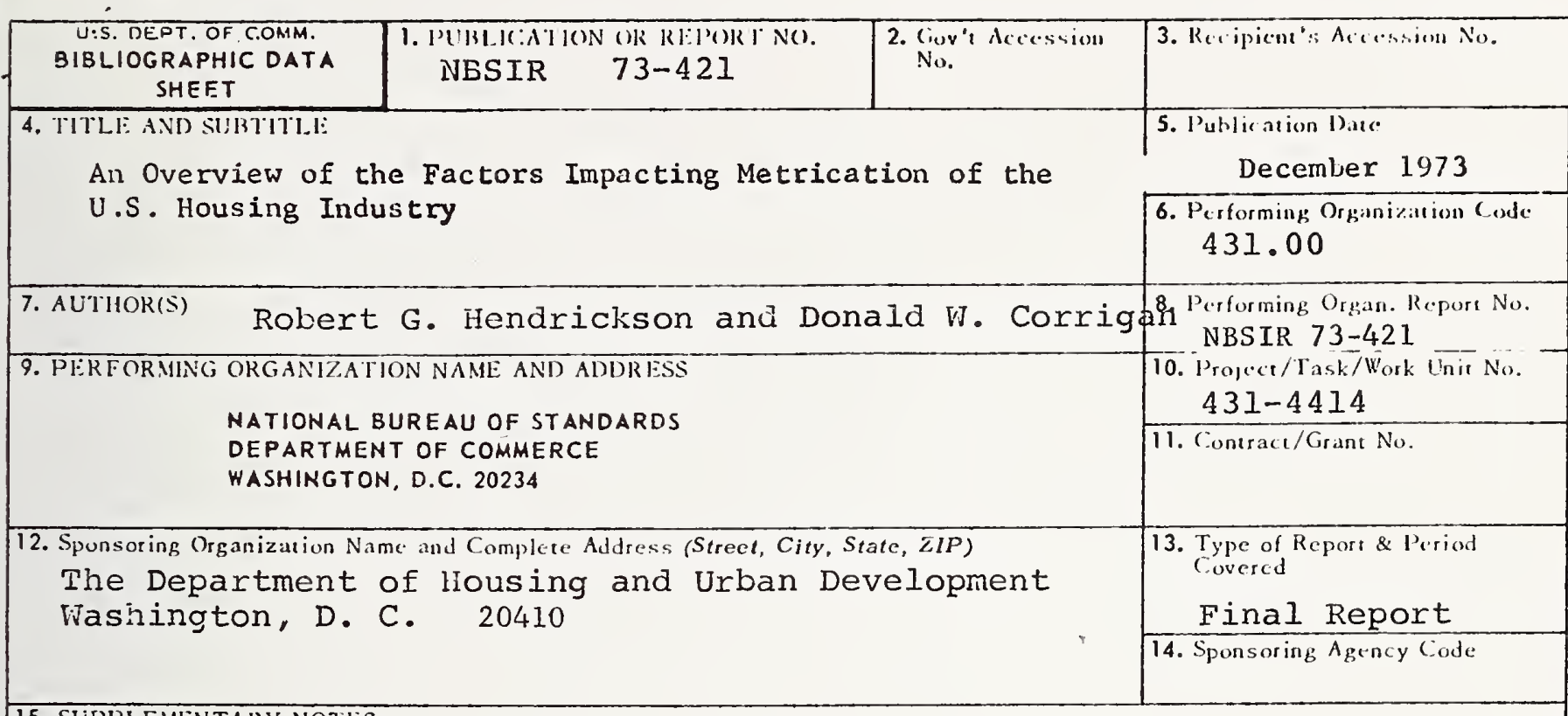

15. SUPPIEMENTARY NOTES

16. ABSTRACT (A 200-word or less factual summary of most significant information. If ciocument includes a significant bibliography or literature survey, mention it here.)

This report describes the vork undertaken by the National Bureau of Standards for the Department of Housing and Urban Development to ascertain and delineate major problems associated with the metrication of the domesting housing industry of tine United States. Source material for tire study included, principally, the foreign experiences of Great Britain and Australia; information outained from interviews with businesses and associations; depositions provided to the 1970 Construction Conference, held for the purposes of the U. S. Metric Study; and documents, both foreign and comestic, pertaining to aspects of metrication

Tine results of the study indicate the critical impact of metrication will be the redefinition or accommodation of the 15,000 codes at the local level, and the coordination of the 127 standardsetting organizations in the United States to define, develop and implement standards consonant with requirements and desired industry goals.

17. KEY WORDS (six to twelve entries; alphabetical order; capitalize only the first letter of the first key word unless a proper name; separated by semicolons) Codes; construction conference; domestic housing, U.S.; foreign metrication; levels of conversion; metrication; problems of metrication.

18. AVAILABILITY i Unlimited

X. For Official Distribution. Do Not Release to NTIS

[- Order From Sup. of Doc., U.S. Government Printing Office Fishington, D.C. 20402, SDC.at. No.Cl3

[ Order From National Technical Information Service (NTIS) Springfield, Virginia 22151

\begin{tabular}{|l|c|}
\hline $\begin{array}{l}\text { 19. SECURITY CLASS } \\
\text { (THIS REPURT) } \\
\text { UNCL ASSIFIED }\end{array}$ & $\begin{array}{c}\text { 21. NO. OF PAGES } \\
\text { 20. SLCURITY CLASS } \\
\text { (TIIS PAGE) }\end{array}$ \\
UNCLASSIFIEI) & 22. PriCC \\
\hline
\end{tabular}





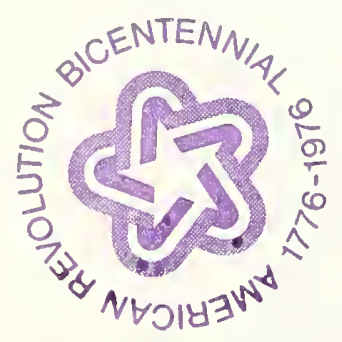

